\title{
Prognostic value of blood gas lactate levels among COVID-19 patients
}

\author{
Nihat Müjdat Hökenek, Rohat AK \\ Department of Emergency Medicine, Kartal Dr. Lütfi Kırdar City Hospital, Istanbul, Turkey
}

Received: 2021-04-04.

Accepted: 2021-07-22

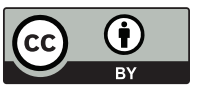

This work is licensed under a

Creative Commons Attribution 4.0 International License

\section{J Clin Med Kaz 2021; 18(4):87-90}

\section{Corresponding author:}

Rohat AK.

E-mail: rohatakmd@gmail.com;

ORCID: 0000-0002-8324-3264

\section{Abstract}

Objective: This study aims to assess the relationship of the blood gas lactate values of the patients who have 2019 coronavirus disease (COVID-19) at the time of admission to the emergency department, to the mortality status of these patients and the intensive care unit requirement.

Methods: This retrospective, observational study was conducted with patients diagnosed with COVID-19 in the emergency department of a tertiary hospital. Once the inclusion and exclusion criteria were applied, 292 patients remained. These patients were divided into 2 groups based on their lactate levels (Lactate $\leq 2 \mathrm{mmol} / \mathrm{L}$ and Lactate $>2 \mathrm{mmol} / \mathrm{L}$ ). Then we compared the groups according to their intensive care unit requirement and mortality status.

Results: Of the 292 patients in this study, the mean age was $68.3 \pm 15.9$, of which 158 were men and 134 were women. In $136(46.6 \%)$ of the patients, hyperlactatemia (lactate $>2$ ) was identified, while in 156 (53.4\%) patients, normal lactate levels (lactate $\leq 2$ ) were seen. The most common comorbidities in the patients were hypertension, diabetes mellitus, and cardiovascular diseases. Intensive care unit requirements and mortality status of the patients in the study, when compared with lactate levels, the mortality and intensive care unit rates of the hyperlactatemia group were statistically higher.

Conclusion: This study discovered that COVID-19 patients who were hyperlactatemic had higher intensive care unit requirement and mortality rates when compared to COVID-19 patients who were nonhyperlactatemic. A larger sample size is required for future prospective studies in order to sufficiently determine the lactate and mortality relationship in patients with COVID-19.

Key words: COVID-19, lactate, intensive care units, mortality

\section{Introduction}

A novel form of coronavirus was identified in December of 2019 in Wuhan, China; this diseasesevere acute respiratory syndrome coronavirus 2 (SARSCoV-2) - rapidly spread around the world [1]. The World Health Organization (WHO) has officially named the disease as 2019 coronavirus disease (COVID-19) [2]. COVID-19 pneumonia can quickly lead to acute respiratory distress syndrome and other serious complications. Acute respiratory distress syndrome (ARDS) that is unresponsive to treatment can lead to multi-organ failure and death [3].

The clinical spectrum of COVID-19 can range from asymptomatic up to the most severe forms of disease:
ARDS, acute heart injury, or acute kidney injury $[3,4]$. Up to $32 \%$ of all positive patients require admission to an intensive care unit (ICU) and death may occur among these patients $[5,6]$. Therefore, early diagnosis of patients at risk of serious illness and potentially life-threatening conditions is important.

The reversible product of anaerobic respiration in glucose metabolism that increases during ischemia is lactate. In case of hypoxia, the formation of NAD (Nicotinamide Adenine Dinucleotide) decreases, thus the NADH / NAD ratio increases and the lactate level increases. Hyperlactaemia is thought to be associated with a metabolic response to stress and an increase in mortality for critically ill patients [7-9]. The fact that 
hyperlactaemia is associated with mortality in critically ill patients has led to the hypothesis whether this biomarker will also be useful in COVID-19 patients.

This study aims to determine the relationship between the blood gas lactate levels at emergency department (ED) admission with the mortality status and ICU admission requirement for patients with COVID-19.

\section{Materials and methods}

This study, which was retrospective, observational, was conducted in the ED of Kartal Dr. Lütfi Kurdar City Hospital between July 1, 2020 and September 1, 2020. The analysis was approved and a waiver of consent was issued by the institutional review board.

All patients who were visited to the ED with COVID-19 from July 1, 2020 to September 1, 2020 were included in the study. The determination of a COVID-19 diagnosis was based on the guidelines by the World Health Organization (WHO) [10]. This study includes only patients who resulted as positive for the real-time Reverse Transcriptase-Polymerase Chain Reaction (RT-PCR) test from both nasal and pharyngeal swab samples. This study contained exclusion criteria: patients who resulted as negative for the RT-PCR test, patients whose lactate level was not checked at the time of admission and patients whose mortality status could not be reached. In addition, patients with conditions such as malignancy, renal and liver failure, and epilepsy that may affect lactate levels were also excluded from the study.

The following data was collected for each patient at the time of admission: age, gender, vital signs, chronic diseases and laboratory tests. The ABL800 FLEX blood gas analyzer (radiometer) was used to measure blood gas lactate levels. The presence of lactate levels over $2 \mathrm{mmol} / \mathrm{L}$ [11] were defined as hyperlactatemia. Patients were divided into 2 groups based on their lactate levels (Lactate $\leq 2 \mathrm{mmol} / \mathrm{L}$ and Lactate $>2 \mathrm{mmol} / \mathrm{L}$ ).
The primary outcome was a 30-day mortality rate and the secondary outcome was determining the relationship between lactate levels and ICU requirement.

\section{Statistical analysis}

Statistical analyzes were made using SPSS 26.0 for Windows. Descriptive criteria, mean and standard deviation are presented as percentage distribution. The Kolmogorov-Smirnov test was used to check the compliance of the data to normal distribution. Chi-square was used for comparison of distributions, the Student's t-test was chosen to compare the mean data when a normal distribution condition was met, and the Mann Whitney-U test was utilized when a normal distribution condition was not met. A $p<0.05$ value was taken for the significance level.

\section{Results}

In the period determined for the study, 292 patients were identified who met the inclusion criteria for this study. Table 1 summarizes the main characteristic findings of the patients. The mean age was $68.3 \pm 15.9,158$ of them were men and 134 were women. The most prevalent comorbidities were cardiovascular diseases (hypertension, ischemic heart disease) and diabetes mellitus (DM).

It was found that in $136(46.6 \%)$ of the 292 patients included in the study had hyperlactatemia (lactate $>2$ ), whereas $156(53.4 \%)$ of the patients had normal lactate levels (lactate $\leq 2)$. Significantly higher neutrophil, white blood cell, and $\mathrm{C}$-reactive protein values were found in the hyperlactatemia group. Additionally, the patient group that had hyperlactatemia were also significantly more likely to experience hypertension.

ICU requirements and mortality status of the patients in the study, when compared according to lactate levels, mortality and ICU rates of the group with hyperlactataemia were statistically higher (Table 2-3) $(\mathrm{p}=0.02)$.

\begin{tabular}{|l|l|l|l|l|}
\hline & $\begin{array}{l}\text { Lactate } \leq 2 \\
\text { ( } \%) \\
\text { Mean } \pm \text { SD }\end{array}$ & $\begin{array}{l}\text { Lactate }>2 \\
(\%) \\
\text { Mean } \pm \text { SD }\end{array}$ & $\begin{array}{l}\text { All n } \\
(\%) \\
\text { Mean } \pm \text { SD }\end{array}$ & p values \\
\hline Sex (Male)a & $78(49,4)$ & $80(50,6)$ & $158(54,1)$ & 0,16 \\
\hline Age (years)b & $69,4 \pm 15,8$ & $67,6 \pm 15,9$ & $68,3 \pm 15,9$ & 0,35 \\
\hline COPDa & $12(66,7)$ & $6(33,3)$ & $18(6,2)$ & 0,33 \\
\hline Asthmaa & $4(36,4)$ & $7(63,6)$ & $11(3,8)$ & 0,36 \\
\hline DMa & $32(43,8)$ & $41(56,2)$ & $73(25,0)$ & 0,08 \\
\hline HTa & $38(42,7)$ & $51(57,3)$ & $89(30,5)$ & 0,02 \\
\hline CHFa & $8(44,4)$ & $10(55,6)$ & $18(6,2)$ & 0,47 \\
\hline CADa & $11(39,3)$ & $17(60,7)$ & $28(9,6)$ & 0,16 \\
\hline CRFa & $17(73,9)$ & $6(26,1)$ & $23(7,9)$ & 0,05 \\
\hline CVDa & $3(50,0)$ & $3(50,0)$ & $6(100,0)$ & 1,0 \\
\hline Alzheimera & $9(50,0)$ & $9(50,0)$ & $18(6,2)$ & 0,81 \\
\hline White blood cell (K/uL)c & $7,1 \pm 3,8$ & $10,2 \pm 6,0$ & $8,4 \pm 5,2$ & 0,001 \\
\hline Neutrophil (K/uL)c & $5,3 \pm 3,3$ & $8,9 \pm 8,5$ & $6,9 \pm 6,6$ & 0,001 \\
\hline NE\%b & $72,1 \pm 13,0$ & $77,7 \pm 18,4$ & $75,1 \pm 14,9$ & 0,003 \\
\hline Lymphocyte (K/uL)c & $1,2 \pm 1,9$ & $1,3 \pm 1,8$ & $1,25 \pm 1,8$ & 0,11 \\
\hline LY\%b & $19,1 \pm 11,8$ & $14,4 \pm 14,0$ & $16,8 \pm 12,5$ & 0,002 \\
\hline Hemoglobin (g/dL)b & $12,1 \pm 2,1$ & $12,7 \pm 3,1$ & $12,4 \pm 2,7$ & 0,09 \\
\hline Platelet (K/uL)c & $208,9 \pm 82,2$ & $233,4 \pm 134,9$ & $219,3 \pm 111,0$ & 0,10 \\
\hline CRP (mg/dL)c & $66,6 \pm 66,9$ & $101,4 \pm 86,7$ & $85,4 \pm 79,4$ & 0,002 \\
\hline
\end{tabular}

aChi square, bStudent t-test, cMann Whitney U test

COPD: Chronic Obstructive Pulmonary Disease, DM: Diabetes Mellitus, HT: Hypertension, CHF: Congestive Heart Failure, CAD: Coronary Artery Disease, CRF: Chronic Renal Failure, CVD: Cerebrovascular Disease, CRP: C-reactive protein 


\begin{tabular}{|l|l|l|l|}
\hline & $\begin{array}{l}\text { Lactate } \leq 2 \\
\mathrm{n}(\%) \\
\text { Mean } \pm \text { SD }\end{array}$ & $\begin{array}{l}\text { Lactate }>2 \\
\mathrm{n}(\%) \\
\text { Mean } \pm \text { SD }\end{array}$ & $\begin{array}{l}\text { All } \\
\mathrm{n}(\%) \\
\text { Mean } \pm \text { SD }\end{array}$ \\
\hline $\begin{array}{l}\text { ICU (-) } \\
\text { ICU (+) }\end{array}$ & $\begin{array}{l}131(84,0) \\
25(16,0)\end{array}$ & $\begin{array}{l}98(72,1) \\
38(27,9)\end{array}$ & $\begin{array}{l}229(78,4) \\
63(21,6)\end{array}$ \\
\hline
\end{tabular}

\begin{tabular}{|l|l|l|l|l|}
\hline & $\begin{array}{l}\text { Lactate } \leq 2 \\
\mathrm{n}(\%) \\
\text { Mean } \pm \text { SD }\end{array}$ & $\begin{array}{l}\text { Lactate }>2 \\
\text { Sayı }(\%) \\
\text { Mean } \pm \text { SD }\end{array}$ & $\begin{array}{l}\text { All } \\
\mathrm{n}(\%) \\
\text { Mean } \pm \text { SD }\end{array}$ & value \\
\hline Non-survivor & $44(28,2)$ & $57(41,9)$ & $101(34,6)$ & 0,02 \\
\hline
\end{tabular}

\section{Discussion}

In this study, the relationship between the lactate levels at ED admission and the outcomes of COVID-19 patients was examined. The 2 groups the patients were divided into were determined by the lactate levels being above or below $2 \mathrm{mmol} / \mathrm{L}$ at the time of admission.

Patients were divided into 2 groups according to their lactate levels above or below $2 \mathrm{mmol} / \mathrm{L}$ at the time of admission. The groups were then compared to each other. The study concluded that patients with hyperlactataemia had higher mortality and ICU rates.

It is important to early determine the ICU requirement and mortality status of COVID-19 patients. For this purpose, there are studies examining the comorbidity of patients. In a study of 5,700 cases of COVID-19 hospitalized in New York, it was reported that the most common comorbidity was hypertension, the second most common was obesity, and following that was diabetes [12]. Additionally, it was reported by the Chinese disease control center that out of a total of 72,314 COVID-19 patients, the average mortality rate was reported to increase from $2.3 \%$ to $5 \%$ and $7.3 \%$ in patients with cardiovascular and diabetic conditions [13]. In this study, the most prevalent comorbidity was hypertension, diabetes and cardiovascular diseases followed this; these results are consistent with the literature. It was emphasized in a study that linked hypertension to COVID-19 that the immune system is compromised by hypertension and COVID-19, and this disorder is exacerbated when blood pressure is not properly controlled [14]. Therefore, blood pressure control seems very important in these types of patients.

In this study, it was found that patients in the group with hyperlactatemia had a higher rate of hypertension. It has been reported in the literature that a positive relationship between lactate and blood pressure exists. It was also reported that lactate concentrations were associated with mean arterial pressure in a cross-sectional study that involved 19 adults [15]. Decreased oxidative capacity leads to a decrease in angiogenesis, then this case it can lead to the formation of hypertension. Since lactate is an indicator of decreased oxidative capacity, high lactate is expected to be more common in patients with hypertension [16].

The usefulness of lactate can be found in many studies from the literature, especially in septic shock patients [17-19]. Although a single lactate measurement at the time of admission was used in our study, studies in the literature showed that lactate levels measured at 1-2 hour intervals give more effective results in critically ill patients [20,21]. In addition, there are studies reporting a positive relationship between lactate levels and length of hospital stay in patients with COPD exacerbations, and a positive relationship between lactate clearance and ED outcome in these patients $[22,23]$. In our study, patients were compared in two groups as those who were with and without hyperlactatemia (lactate $>2 \mathrm{mmol} / \mathrm{L}$ ) according to their lactate values at the time of ED admission. Mortality and ICU requirement rates were higher in patients with hyperlactatemia; these results are consistent with studies found in the literature.

As with any retrospective study, there are some limitations. The sample size of this single center study was relatively small; therefore, studies with a larger sample size are required in order to confirm these results.

\section{Conclusion}

The COVID-19 pandemic has caused a serious mortality and morbidity problem worldwide. It was found that COVID-19 patients who were hyperlactatemic had both a higher ICU requirement and higher mortality rates when compared to patients who were non-hyperlactatemic. In order to appropriately assess the lactate and mortality relationship in COVID-19 patients, prospective studies should take a larger sample size.

Disclosures: There is no conflict of interest for all authors.

Acknowledgements: None.

Funding: None.

\section{References}

1. Huang C, Wang Y, Li X, Ren N, Zhao Jet al. Clinical features of patients infected with 2019 novel coronavirus in Wuhan, China. Lancet. 2020; 395(10223):497-506. doi: 10.1016/S0140- 6736(20)30183-5.

2. Grasselli G, Pesenti A, Cecconi M. Critical care utilization for the COVID-19 outbreak in Lombardy, Italy: Early experience and forecast during an emergency response. JAMA: e Journal of the American Medical Association. 2020. doi:10.1001/ jama.2020.4031

3. Ak, R., Kurt, E., \& Bahadirli, S. Comparison of 2 Risk Prediction Models Specific for COVID-19: The Brescia-COVID Respiratory Severity Scale Versus the Quick COVID-19 Severity Index. Disaster Medicine and Public Health Preparedness. 2021; 1-5. https:// doi.org/10.1017/dmp.2021.141 
4. WangD, HuB, HuC, ZhuF, LiuX etal. Clinical characteristics of 138 hospitalized patients with 2019 novel coronavirus- infected pneumonia in Wuhan, China. JAMA: e Journal of the American Medical Association. 2020; 323(11):1061-1069. doi: 10.1001/ jama.2020.1585

5. Doğanay, F., Elkonca, F., Seyhan, A. U., Y1lmaz, E., Batırel, A., \& Ak, R. Shock index as a predictor of mortality among the Covid-19 patients. The American journal of emergency medicine. 2021; 40:106-109. https://doi.org/10.1016/j.ajem.2020.12.053

6. Ye Q, Wang B, Mao J. e pathogenesis and treatment of the 'Cytokine Storm' in COVID-19. e Journal of Infection 2020; 80(6):607-613. doi: 10.1016/j.jinf.2020.03.037

7. Khosravani, H., Shahpori, R., Stelfox, H. T., Kirkpatrick, A. W., \& Laupland, K. B. Occurrence and adverse effect on outcome of hyperlactatemia in the critically ill. Critical Care. 2009; 13(3):1-5. https://doi.org/10.1186/cc7918

8. Cerović, O., Golubović, V., Špec-Marn, A., Kremžar, B., \& Vidmar, G.. Relationship between injury severity and lactate levels in severely injured patients. Intensive care medicine. 2003; 29(8):1300-1305. https://doi.org/10.1007/s00134-003-1753-8

9. Nguyen, H. B., Rivers, E. P., Knoblich, B. P., Jacobsen, G., Muzzin, A., Ressler, J. A., \& Tomlanovich, M. C. Early lactate clearance is associated with improved outcome in severe sepsis and septic shock. Critical care medicine. 2004; 32(8):1637-1642. https://doi. org/10.1097/01.CCM.0000132904.35713.A7

10. World Health Organisation (WHO) Laboratory testing for coronavirus disease 2019 (COVID-19) in suspected human cases. Geneva. Interim guidance 19 March 2020. Available at https://www.who.int/emergencies/diseases/novel-coronavirus-2019/technical-guidance/ laboratory-guidance $\backslash$ Accessed 15 March 2020.

11. Sakal, C., Ak, R., Taş̧̧ı, A., Deniz Kırkpantur, E., Ünal Akoğlu, E., \& Cimilli Ozturk, T. Admission blood lactate levels of patients diagnosed with cerebrovascular disease effects on short and long-term mortality risk. International Journal of Clinical Practice. 2021; e14161. https://doi.org/10.1111/ijcp.14161

12. Richardson, S., Hirsch, J. S., Narasimhan, M., Crawford, J. M., McGinn, T., Davidson, K. W., Zanos, T. P. Presenting characteristics, comorbidities, and outcomes among 5700 patients hospitalized with COVID-19 in the New York City area. Jama. 2020; 323(20):20522059. https://doi.org/10.1001/jama.2020.6775

13. Wu, C., Chen, X., Cai, Y., Zhou, X., Xu, S., Huang, H., Song, Y. Risk factors associated with acute respiratory distress syndrome and death in patients with coronavirus disease 2019 pneumonia in Wuhan, China. JAMA internal medicine. 2020; 180(7):934-943. https:// doi.org/10.1001/jamainternmed.2020.0994

14. Guzik, T. J., Mohiddin, S. A., Dimarco, A., Patel, V., Savvatis, K., Marelli-Berg, F. M., McInnes, I. B. COVID-19 and the cardiovascular system: implications for risk assessment, diagnosis, and treatment options. Cardiovascular research. 2020; 116(10):1666-1687. https:// doi.org/10.1093/cvr/cvaa106

15. Baron AD, Brechtel-Hook G, Johnson A, Hardin D. Skeletal muscle blood ow. A possible link between insulin resistance and blood pres- sure. Hypertension. 1993; 21:129-135. https://doi.org/10.1161/01.HYP.21.2.129

16. Juraschek, S. P., Bower, J. K., Selvin, E., Subash Shantha, G. P., Hoogeveen, R. C., Ballantyne, C. M., Young, J. H. Plasma lactate and incident hypertension in the atherosclerosis risk in communities study. American journal of hypertension. 2015; 28(2):216-224. https://doi.org/10.1093/ajh/hpu117

17. Ryoo, S. M., Lee, J., Lee, Y. S., Lee, J. H., Lim, K. S., Huh, J. W., Kim, W. Y. Lactate level versus lactate clearance for predicting mortality in patients with septic shock defined by sepsis-3. Critical care medicine. 2018; 46(6), e489-e495. https://doi.org/10.1097/ CCM.0000000000003030

18. Woolum, J. A., Abner, E. L., Kelly, A., Bastin, M. L. T., Morris, P. E., Flannery, A. H. Effect of thiamine administration on lactate clearance and mortality in patients with septic shock. Critical care medicine. 2018; 46(11):1747-1752. https://doi.org/10.1097/ CCM.0000000000003311

19. Hernández, G., Ospina-Tascón, G. A., Damiani, L. P., Estenssoro, E., Dubin, A., Hurtado, J., Bakker, J. Effect of a resuscitation strategy targeting peripheral perfusion status vs serum lactate levels on 28-day mortality among patients with septic shock: the ANDROMEDASHOCK randomized clinical trial. Jama. 2019; 321(7):654-664. https://doi.org/10.1001/jama.2019.0071

20. Vincent JL, Quintairos E, Silva A, Couto Jr L, Taccone FS. The value of blood lactate kinetics in critically ill patients: asystematic review. Crit Care. 2016; 20:257. https://doi.org/10.1186/s13054-016-1403-5

21. Ibrahim, A., Bayramoglu, B., Hokenek, N. M., \& Tekyol, D. Lactate clearance during the first 2 hours after hospital admission: A useful biomarker for predicting 30-day mortality in patients with diabetic ketoacidosis. International Journal of Clinical Practice. 2021; e14204. https://doi.org/10.1111/ijcp.14204

22. Seda Beyhan Sagmen, Tugba Naziroglu. Relationship between lactate level and length of hospital stay in patients with a COPD exacerbation. J Clin Med Kaz. 2020; 3(57):19-23. https://doi.org/10.23950/1812-2892-JCMK-00733

23. Durmuş U, Nurettin ÖD, Pekdemir M, Yılmaz S, Yaka E, Karadaş A, Pınar SG. The value of lactate clearance in admission decisions of patients with acute exacerbation of COPD. American Journal of Emergency Medicine. 2018; 36(6):972-976. https://doi.org/10.1016/j. ajem.2017.11.002 